Article

\title{
An Exploratory Qualitative Exploration of the Personal Values Underpinning Taiwanese and Malaysians' Wine Consumption Behaviors
}

\author{
Miranda Mirosa ${ }^{*}{ }^{\dagger}$ and Sharon Tang ${ }^{\dagger}$ \\ Received: 23 September 2015; Accepted: 8 January 2016; Published: 18 January 2016 \\ Academic Editor: Lorenzo Stafford \\ Department of Food Science, University of Otago, Dunedin, 9016, New Zealand; sharon.tang@otago.ac.nz \\ * Correspondence: miranda.mirosa@otago.ac.nz; Tel.: +64-(0)3-479-7953 \\ + These authors contributed equally to this work.
}

\begin{abstract}
Augmented buying power of East Asian consumers has resulted in increased interest in these markets. Wine is a particularly promising sector to target as the number of East Asians choosing to drink wine rises. In order to serve these markets, companies must understand factors influencing consumers' choices. The objective of this research was to understand how Taiwanese and Malaysian consumers' personal values influenced their consumption decisions about wine. The means-end chain framework and associated semi-structured interview technique, value laddering, was used to elicit consumers' preferred product attributes, the consequences of these attributes and the values that underpin these consequences. Data collection involved intercepting foreign travelers from Malaysia and Taiwan in New Zealand (20 Taiwanese and 20 Malaysian) to partake in a wine choice interview. The resulting findings are exploratory in nature. Analysis revealed the most preferred wine attributes for Taiwanese were "Price" and "Sensory Aspects"—-that these attributes were linked to consequences "Financial Considerations" and "Satisfy Senses"-which in turn were linked to personal values "Self Direction" and "Achievement". For the Malaysian participants, the attribute "Sensory Aspects" of wine was most important, as was the value "Hedonism". This study adds to literature related to beverage consumption decision making by exploring cultural aspects. It also offers suggestions for practitioners interested in targeting these consumers.
\end{abstract}

Keywords: cross-cultural; Asian; wine choice; means-end chain; soft laddering; values

\section{Introduction}

The recent economic growth of Asian countries has generated a great demand for imports of intermediate and primary commodities as consumer behavior and consumption patterns shift. One such commodity is grape wine. The grape wine industry, which has held a small presence in the East Asian region until recently, has seen a rapid growth in the Asian market. Increased alcohol consumption in Asian countries has created many opportunities for exporting wine industries around the world in the last few years. The wine market in China, for example, is currently valued at over US $\$ 10$ billion, and is predicted to reach US \$19 billion by 2016 [1]. Less populous but prosperous countries, such as Singapore, Malaysia, Hong Kong, Taiwan and Korea have also seen a rise in wine consumption, in particular premium wines [2]. Seven out of 15 top-ranked countries, in terms of unit value of wine imports, were Asian countries with Hong Kong, Singapore and Taiwan ranked amongst the top five [2].

Winemakers must be consumer-oriented to enable them to have a strong footing in the Asian wine market. An important aspect of being consumer-orientated is understanding the purchase motivations for particular products. Given that motivations are linked to consumers' deep-seated 
values, it is crucial for winemakers to understand the most important underlying personal values that underpin consumption behavior. In this study, the means-end chain framework is used to explore the underlying personal values of consumers from two East-Asian countries that show great potential for growth in forthcoming years, Taiwan and Malaysia. These understandings will in turn, help to understand consumers' needs and wants with regards to wine consumption. Specifically, the overall objective of this research is to understand how Taiwanese and Malaysian consumers' personal values influence their consumption decisions about wine. The sub-objectives are twofold: (1) to contribute to the understanding of means-end chain literature related to food purchasing processes by exploring the influence of Taiwanese and Malaysian culture on means-end chain for wine choice; and (2) to offer practitioner-orientated suggestions to wine exporters interested in targeting the East Asian countries-Taiwan and Malaysia.

Taiwan and Malaysia were the chosen East-Asian countries for four reasons. Firstly, they both look set to experience increased wine sales in forthcoming years. Secondly, the research was conducted in New Zealand and a recent agreement which allows New Zealand wine to have tariff-free access to Taiwan gave the researchers an even more compelling reason to understand the underlying values which drive Taiwanese consumers' wine consumption decisions. Thirdly, Malaysia was included in the study for cross cultural purposes and was an obvious choice given the cultural understanding and linguistic capability of the second author who is born Chinese Malaysian. Lastly and importantly, the motives of wine drinkers from these countries have received almost no academic attention in the Western literature.

In order to be able to understand the most important underlying personal values that underpin consumption behavior, means-end chain theory and "laddering" methodology, developed to identify means-ends chains, were deemed to be the most appropriate tools to use. There are a few studies that have investigated a wider range of values in relation to East Asian consumption behaviors or wine drinking behaviors. In laddering only the relevant behaviors are predefined in the research and the values are uncovered by repeated questioning or probing about why particular things are done or are seen to be important. The behavior (means to the end) is first described by the respondent who is then probed as to "why" they behave in that way. This normally uncovers some conscious rationalization of the behavior and this rationalization is then probed as to why that is important to the individual. The underlying reasons, where a respondent can genuinely articulate them, can be associated with their fundamental underlying values. Ultimately, the aim of the questioning was to get participants to think critically about what their motivations were for the wine purchase behaviors, thereby allowing the interviewers to identify the underlying drivers or barriers for the behaviors. In the remainder of this section, a brief overview of the Taiwanese and Malaysian wine markets is firstly presented before moving on to consider the extant literature on Asian consumers' wine behaviors. The theoretical framework, means-end chain, is then introduced and discussed with regards to culture. Findings from the extant literature on the key attributes, consequences and values driving non-Asian wine behaviors are then provided.

\subsection{Taiwanese Wine Market}

Given a paucity of academic literature on Taiwanese consumers' wine drinking habits, the following summary of the Taiwanese wine market is based on a review of the Australian Trade Commission (2015) report [3] which provides the most up-to-date market intelligence available. The current data shows the total population in Taiwan in 2014 is 23.36 million [4]. Wine constitutes less than $25 \%$ of the total value of alcohol consumption in Taiwan (with whisky mostly imported from Scotland generally being a more popular choice). Despite this, Taiwan is still Asia's fifth largest consumer of wine. In the past six years, overall wine consumption has grown at a rate of 8.6 per cent per annum. Moreover, wine sales in Taiwan are forecasted to continue to increase in conjunction with a rise in living standards and increased cosmopolitanism, as professionals and women join the ranks of high income earners that enjoy consuming wine. 
Taiwanese consumers generally have a preference for red over white wine, with $48 \%$ of the import volume consisting of cabernet sauvignon or similar blends. There is also a general preference for full bodied wines compared to light bodied wines. Even though the current wine market shows that warm climate wines are better received than cooler climate wines, there is an increasing appreciation for cool climate wines.

Special attention has also been given to the preference of wine bottle and label design, with a preference for slimmer or reserve tapered bottles compared to short and light bottles. Taiwanese consumers also have a general preference for natural cork compared to other methods of corkage such as synthetic cork or screw cap, although a growing acceptance on screw cap has been observed. Drinking habits are reported to be changing as most new consumers have yet to develop a fixed preference for the source of wine. A recent report by Global Agricultural Information Network has also contended a growing interest in sweeter wines with unique history backgrounds, such as ice wine [5].

\subsection{Malaysian Wine Market}

According to New Zealand Trade and Enterprise [6], Malaysia comprises of a population of 27.7 million people and approximately 65\% Malay, 27\% Chinese and eight percent Indian. The Malays are predominantly Muslim, and due to religious reasons, they are not permitted to consume alcoholic drinks. However, the Malaysian Chinese who make up around seven million of the population, form a firm target base for imported wine [6,7].

The report [6] also contended that the wine drinking culture in Malaysia will become more popular over the next few years. Wines are becoming more commonly accepted at international outlets, where the foods served are steaks or other international cuisine.

However, wine is still not commonly consumed in most Malaysian households as wines are generally considered as "social drink", and are only usually consumed during special occasions. On an interesting note, the consumption of red wine in Malaysia has increased over the recent years, mainly due to the perceived health benefits of drinking red wine [8].

According to this report [8], economy wine brands attract consumers by using marketing means, such as competitive pricing and promotions, for example buy-one-get-one-free and free gifts. Additionally, premium brands are packaged and positioned as being high quality products and are promoted during special events such as wine tastings in high class restaurants and hotels. It has also been noted that private label brands remained very limited [7].

\subsection{Chinese Wine Market}

While current research on Taiwanese and Malaysian wine drinking behaviors has come from Trade Commission reports, academic attention has been given to the Chinese wine drinking market. Given Taiwan and Malaysia are more culturally and historically similar to China than to other Western countries where the bulk of research on wine consumption has been conducted to date, the information available in existing literature in the Chinese context was examined as well in order to obtain further possible insights relevant to the populations of interest for this study. A research study found that the Chinese community typically has poor general knowledge about wine with two thirds of the participants, being unaware of the existence of white wine [9]. Similarly, Fu [10] has noted that most Chinese think red wine represents the entire wine category.

According to Liu and Murphy [9], Chinese consumers consume red wine for special occasions such as Chinese (Lunar) New Year and other special holidays. Red wine is the wine of choice and is consumed during these occasions. Red wine, for instance, is an auspicious color in the Chinese culture, associated with happiness and celebrations, whereas white is considered as an unlucky color, often associated with funerals and death. Chinese consumers also consume red wine for its image portrayal, which is considered trendy and shows that the consumer has good taste, all of which would contribute to having "Mian Zi" (face). Both Liu and Murphy [9] and Balestrini and Gamble [11] found that having limited wine knowledge meant that Chinese consumers would typically rely on the extrinsic cues of 
wine, such as price and country of origin, to help them make their choice, instead of more intrinsic cues such as taste.

\subsection{Introduction and Overview of the Means-End Chain Theoretical Model}

The means-end chain model is a theoretical model which allows researchers to understand how attributes, consequences and values can be systematically categorized to form a simple network of association [12]. Researchers are able to observe and understand how the attribute of a product can be used to meet the personal value of an individual, hence understanding the reason a consumer might choose a certain product attribute. The concept of levels of abstraction is embodied in this means-end chain framework: attribute has the lowest level of abstraction, is linked to consequence, which has a higher level of abstraction, and in turn is linked to value, which has the highest level of abstraction [12]. Given that the perception of food is widely and deeply influenced by culture, food and beverage preferences between cultures can differ widely [13]. In order to gain full understanding of the influence of culture in this means-end chain model, Overby and colleagues [14] developed the means-end chain framework to include the influence of culture. The inclusion of analyzing the influence of culture in all parts of the attribute, consequence and value ladders allows researchers to understand how consumers organize their thoughts and structure their knowledge about a product [15] and should therefore be used in cross-cultural studies. Overby and colleagues used this framework to understand wine choice in a cross-cultural context, in a comparative study between American and French consumers' wine consumption behaviors [14]. Additionally, this model has been previously shown to be a useful tool for analyzing consumer behavior in the food domain [16-21]. The current study extended on Overby and colleagues' cross cultural wine drinking [14] work by investigating wine consumption habits in an East Asian context (Taiwanese and Malaysian). It is important to first consider available literature on the attributes consequences and values driving non-Asian wine behaviors for purpose of comparative purposes.

\subsection{Extant Literature on the Key Attributes Consequences and Values Driving Non-Asian Wine Behaviors}

A previous means-end chain study investigating New Zealander's wine purchase motivations [22] revealed that for the New Zealand participants, the primary attribute that drove consumers to purchase and consume wine was "Sensory Aspects" of wine, followed by "Price" and "Occasion". All three of these attributes were surface level characteristics that are typically associated to the purchase of alcohol [23]. These considerations have been found in the literature to appear in more general food purchase decisions as well [24,25]. These aforementioned attributes were justified at the next level of abstraction by various consequences, such as "Financial Considerations", "Assuring Quality" and "Satisfying Senses". Two major Schwartz's values that appeared in the New Zealand participants' Hierarchical Value Maps were "Hedonism" and "Achievement". The first of these values indicates that New Zealand consumers are highly driven by enjoyment and pleasure when consuming wine. The second of these values indicates that they also aspire to achieve their goals through having wine qualities that meet their expectations.

Next, the study's methodology and findings are presented and the paper concludes by making marketing recommendations for practitioners.

\section{Experimental Section}

An overview of the study design is provided in Table 1 which details all of the key decisions made during the data collection and analysis phase. The table and the remainder of this methodology section are organized into the three main steps of this study: pre-interview phase, in the field, and post-interview phase. 
Table 1. Overview of Study Design and Core Decisions Made at Each Step of the Process.

\begin{tabular}{|c|c|}
\hline Study Design & Core Decisions Made at Each Step \\
\hline \multicolumn{2}{|r|}{ Pre-Interview Phase } \\
\hline $\begin{array}{l}\text { Sample Selection and } \\
\text { Recruitment }\end{array}$ & $\begin{array}{l}20 \text { participants recruited from each country (Malaysia and Taiwan). } \\
\text { Intercept technique at Christchurch Airport was used (as well as snowball sampling) } \\
\text { to recruit. } \\
\text { Inclusion criteria were: (1) Over } 18 \text { years of age, (2) Originally from Malaysia or } \\
\text { Taiwan, (3) Have been in New Zealand for not more than a year, and (4) Have } \\
\text { experience in purchasing wine. }\end{array}$ \\
\hline Interview Environment & $\begin{array}{l}\text { A series of guidelines were adapted from Reynolds and Gutman [24] to ensure cultural } \\
\text { sensitivity and to create an appropriate and standardised environment for } \\
\text { the interviews. }\end{array}$ \\
\hline Interview Techniques & $\begin{array}{l}\text { A "Soft Laddering" interview was conducted face-to-face. } \\
\text { A situational context was given to the participants, where they were required to } \\
\text { imagine themselves purchasing wine in a restaurant setting. }\end{array}$ \\
\hline \multicolumn{2}{|r|}{ In The Field } \\
\hline Interview Process & $\begin{array}{l}\text { Interviews were conducted in either English or Mandarin. } \\
\text { The sequence of the interview process was: (1) Laddering interview; } \\
\text { and (2) Socio-Demographic Survey. }\end{array}$ \\
\hline \multicolumn{2}{|r|}{ Post-Interview Phase } \\
\hline Transcription and Translation & $\begin{array}{l}\text { Interviews conducted in Mandarin were transcribed in Mandarin before translating } \\
\text { into English. } \\
\text { Five Mandarin transcripts were cross-checked with a Chinese-English speaker. }\end{array}$ \\
\hline $\begin{array}{l}\text { Coding: (code generation, } \\
\text { code revision and code } \\
\text { definition and naming) }\end{array}$ & $\begin{array}{l}\text { Data was coded using NVivo10. } \\
\text { Relevant data was coded into pre-determined codes. } \\
\text { The decision to combine or expand codes was decided after revision and discussion. } \\
\text { Codes that could not be defined were carefully considered and decisions were made } \\
\text { whether to assign the code to an existing code or if the creation of a new code } \\
\text { was required. }\end{array}$ \\
\hline Interpretation Technique & $\begin{array}{l}\text { Hierarchical Value Maps were created for the two cultural groups. } \\
\text { Information on Socio-Demographic Information Survey was aggregated and organized } \\
\text { into a table. }\end{array}$ \\
\hline
\end{tabular}

\subsection{Pre-Interview Phase: Study Design}

\subsubsection{Sample Selection and Recruitment}

Forty participants (20 Malaysians and 20 Taiwanese) were recruited at the Christchurch International Airport in New Zealand to participate in this study. Given the study was conducted by researchers living in New Zealand, talking to East Asian travelers in New Zealand made sense from a practical standpoint given their availability for sampling. Two non-probability sampling techniques were used to recruit research participants. Any potential participant who sounded like Malaysian or Taiwanese was approached by the researcher using the intercept technique. Snowball sampling was also adopted to recruit participants by the spread of words to travelers from the same travel group. Screening questions were used to determine their suitability to participate in the interview. These screening questions were: (1) over 18 years of age; (2) originally from Taiwan or Malaysia; (3) in New Zealand for not more than one year; and (4) experienced in purchasing wine. The inclusion criteria of having been in New Zealand for not more than a year was set to reduce the likelihood that participants have been substantially influenced by New Zealand culture. Quota sampling was used and once the sample size has increased, an effort was made to screen participants to widen the spread of demographics, particularly using age and gender as a guide, as is often done in qualitative studies [26]. Existing laddering research suggested that a minimum sample of 20 participants included in each sub-group is sufficient to provide rich information about consumer choice [27]. Given that each respondent typically provides about 3 ladders, and ladders usually have an average of 5 elements, ladders from 20 respondents can produce a minimum of 225 data points [27]. This means that even a 
relatively small sample size of 20 participants can provide considerable detail about consumer choice. The sample size used in this study was found to be sufficient to reach data saturation in terms of identifying the values and their consequences.

\subsubsection{Interview Environment}

Reynolds and Gutman's [28] suggestions for conducting a value laddering interviewing were adapted to help guide this study. These were: (i) creating a non-threatening environment; (ii) creating a slight sense of vulnerability on the part of the interviewer; (iii) maintaining control of the interview; (iv) creating a sense of involvement and caring in the interview; and (v) creating a non-misleading interview environment.

\subsubsection{Interview Technique}

The interviews adopted a semi-structured, open-ended, soft value laddering technique to uncover the underlying consequences and values that influenced participants' wine choices. Although soft laddering is a laddering method which requires a more skilled interviewer than hard laddering to collect data (in hard laddering the participants are forced to produce ladders and to respond in higher levels of abstraction [29], soft laddering does provides participants with more freedom of expression and as such is deemed to be more appropriate for exploratory work [30]. The soft-laddering interview technique allowed the participants to move back and forth between the different levels of abstraction (i.e., between attributes, consequences and values). This was the recommended technique in cases where the cognitive structure of the participants are weak due to low involvement [25], as is this case of Taiwanese and Malaysian participants who are less familiar to wine.

\subsection{In the Field}

\subsubsection{Interview Process}

Participants who had met the selection criteria were invited to sit in a quiet spot for the interview to commence.

After initial introductions and explanations of the interview process, the participants were given a scenario in which they would have to imagine choosing and purchasing a glass of wine in a restaurant:

"Imagine you are in a restaurant, and you are given a wine list by the waiter to choose your wine from. What are the characteristics or aspects of the wine would you consider before choosing your glass of wine?"

Creating a background scenario allowed the participants to have a relatable situation to move the participants up the attributes, consequences and values ladder.

The participants were then first asked to describe the attributes related to the wines that would influence their purchase, and then the interviewer questioned the participants for the reasons for choosing these attributes. Continuously probing participants (e.g., by asking them a series of "why?" questions) helped to move the participants" thinking to a higher level of abstraction. Eventually the underlying values which influenced their wine decision making process were uncovered. The method of continuously questioning the participants also forced the participants to think critically about the connections between the product attributes and the fulfillment of an end-state they desired in a restaurant.

Other data collected during the interviews include the participants' socio-demographic information, frequency of dining in a restaurant, frequency of drinking wine and their wine involvement score. Participants' wine involvement score was calculated to understand the participants' involvement level with regards to wine consumption (to allow for comparisons to be made between sample populations). A similar question and rating style to Zaichowsky's [31] involvement scale was used, where five questions about the participants' involvement in wine products were asked with 
participants required to rate their answers on a scale of 1 to 7 . The interviews were conducted by one researcher in either English or Mandarin, depending on the tongue most comfortably spoken by the participants. All interviews were recorded for later transcription and translation. The whole session lasted between 25 and $40 \mathrm{~min}$.

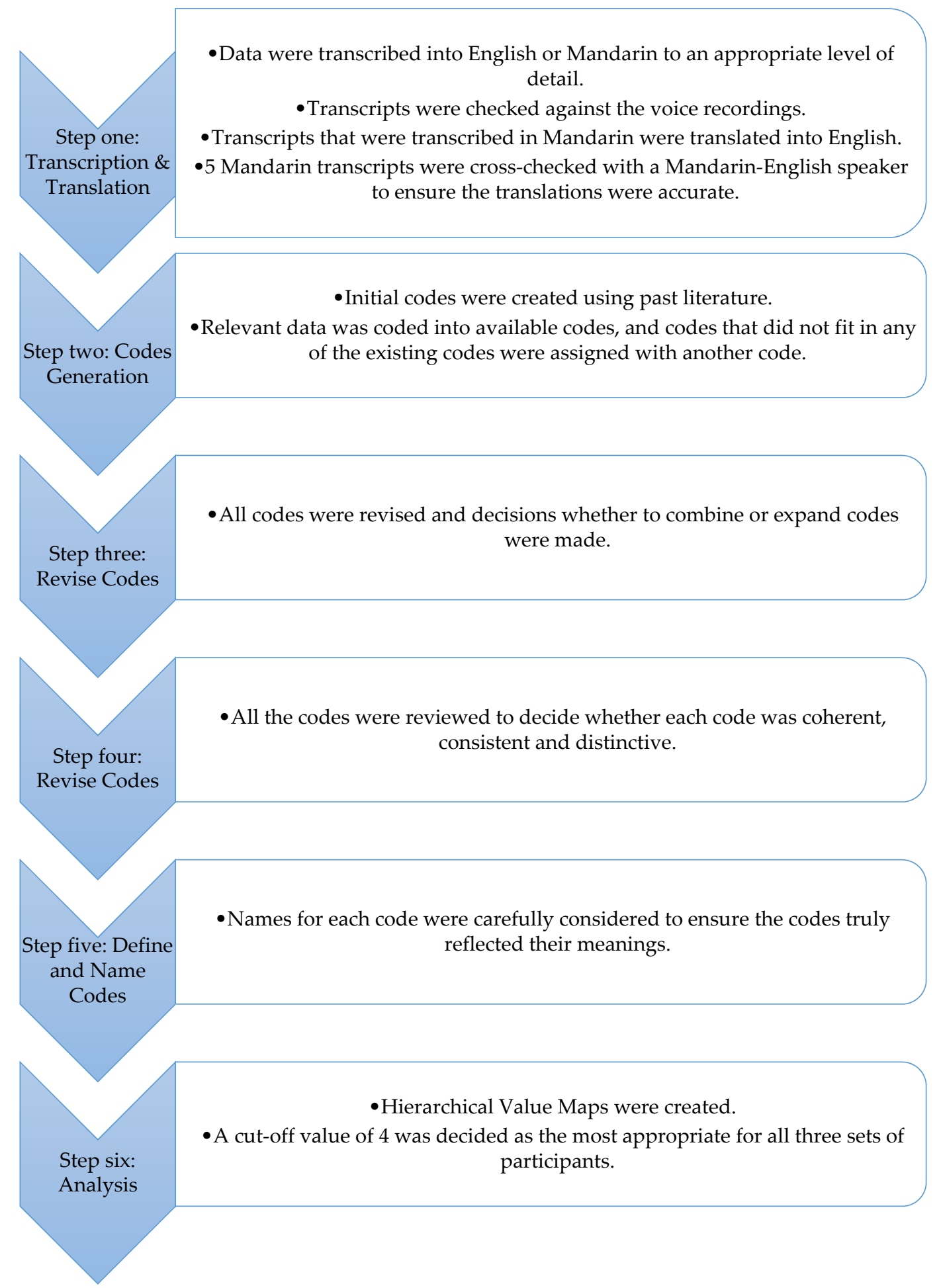

Figure 1. Process of Thematic Analysis of Data from Taiwan and Malaysia. 


\subsubsection{Post-Interview Phase: Data Analysis}

This study used an adapted version of Braun and Clarke's [32] thematic six-step content analysis approach (see Figure 1) in the transcription, translation, coding and analysis process.

Step one involved reading the transcripts once before the coding, for the coder to be familiar with the data and also to understand the meaning of the participants' responses. All interviews were transcribed in Microsoft Word and the interviews that were conducted in Mandarin were transcribed in Mandarin and then translated to English. Five of the translated English version transcripts were crossed-checked with the Mandarin version, by a bi-cultural Chinese-English reader to ensure that the meaning from the data was not lost after translation.

In order to be able to critically study the cultural impact of the methods, the method of direct translation of Mandarin interviews (which would reduce the time and steps involved for data processing) was rejected. This method was not suitable as any cultural-related meaning to a sentence may be lost during translation. Therefore by having the option to further analyze the text in its original language, the researcher was able to understand the concept forwarded by the participants in a culturally relevant context. The translator had good cultural background understanding of all two cultures of interest and was culturally informed to be able to conceptualize the contextual meaning of the interviews, as suggested by literature [33].

The data was organized and coded using the software program NVivo10. To address the problem of intra-coder reliability [34], codes were double-coded with the researcher coding the data segments at two different time periods.

The codes were assigned using Reynolds and Gutman's [28] three levels of analysis framework: attributes, consequences, and values. Both the attributes and consequences were analyzed according to Braun and Clarke's [32] thematic six-step content analysis approach, and the values were coded using the existing Schwartz's [35] Universal List of Values Framework as this list provided a wide selection of values and had been tested in different cultures, including Asian cultures [36].

In Step two, initial codes were generated for identified attributes, consequences, and values. This initial identification of codes was both "data-driven" and "theory-driven", meaning that potential codes were firstly identified from the existing literature [14,23], and then new codes were also generated if the data from the interviews did not fit into the existing coding structure.

Step three was an iterative process which involved revising all the code contents for each code and deciding whether combining or expanding the codes where appropriate.

In Step four, after all data had been coded into appropriate codes, a process of reviewing and refining codes was carried out. The coder re-read all the interview excerpts that were coded into each code, and considered the appropriateness of the codes. If the code did not fit into the code, the excerpt was discussed with another researcher to decide if the content should be moved into a more appropriate existing code or if a new code should be created. This also assisted in the decision on whether the code was to be discarded from the analysis or not. Once decisions to merge codes were made, the researcher ensured that before doing so, notes were taken to document both the initial coding structure and the changes made. Any uncertainty from coding was discussed with another researcher to ensure that the appropriate allocation of codes was performed. Once all the data was allocated into all the appropriate codes, the researcher moved on to refining the codes. The refining process involved an analysis of whether all the codes were accurately represented. This was done by re-reading the entire data set within each code, and further reviewing and refining the coding structure. This was also where any potential new codes were identified and considerations were made as to whether these new codes were relevant to the datasets.

Once the codes appeared cohesive and meaningful, the researcher moved on to Step five. This process involved accurately naming the codes to ensure each name fully reflected the "essence" of each code. A discussion with the co-researcher was held once more to decide whether the name of the codes were representative of the material within. 
In Step six, the final step of the process, data analysis was carried out. NVivo10 was used to create the Hierarchical Value Maps, which represent a pictorial display of the aggregated means-end chains for thinking about wine consumption in a restaurant setting. The Matrix Coding function in NVivo10 was used to show the number of links between each attribute, consequence and value. Separate matrix coding analyses were done for Attributes-Consequences links and Consequences-Values links for the Taiwanese and Malaysian cultural groups. Following that, Hierarchical Value Maps were constructed for the two cultures to represent these links. The Hierarchical Value Maps were constructed according to the three main abstraction levels: attributes, consequences and values (refer to Figures 2 and 3). The cut-off of four was chosen for the Hierarchical Value Maps as it provided the most informative and relevant information to be displayed clearly in the Hierarchical Value Maps.

\section{Results and Discussion}

\subsection{Participants' Characteristics}

Table 2 shows the participants' reported gender, age and level of education, and also the ratings of how frequently they dine in a restaurant, drink wine at home, and the average number of glasses of wine they typically consume in one sitting in a restaurant, as well as their wine involvement score. The results from Table 2 show that both Taiwanese and Malaysian participants were quite similar in several aspects, such as the majority of participants had finished university, and they shared similar wine drinking frequency at home, visited the restaurant 1-3 times per month, and more than half of the participants consumed around 1-3 glasses of wine in a restaurant. The wine involvement score for both cultural groups were reasonably similar. This shows that the characteristics of these two cultural groups were quite similar and therefore a comparison of the two Hierarchical Value Maps is reasonable.

Table 2. Characteristics of Participants.

\begin{tabular}{|c|c|c|}
\hline & Taiwan & Malaysia \\
\hline Participant Ratio (Male:Female) & 9:11 & $10: 10$ \\
\hline Average Age (Year) & 31 & 40.6 \\
\hline \multicolumn{3}{|l|}{$\begin{array}{l}\text { Level of Education } \\
\text { (\# Participants) }\end{array}$} \\
\hline Secondary & $2(10 \%)$ & $3(15 \%)$ \\
\hline University & $14(70 \%)$ & $16(80 \%)$ \\
\hline Other (e.g., trade school) & $4(20 \%)$ & $1(5 \%)$ \\
\hline \multicolumn{3}{|l|}{$\begin{array}{c}\text { Frequency of Dining in a Restaurant } \\
\text { (\# Participants) }\end{array}$} \\
\hline$<1$ time a month & $2(10 \%)$ & $7(35 \%)$ \\
\hline 1-3 times a month & $10(50 \%)$ & $9(45 \%)$ \\
\hline $4+$ times a month & $8(40 \%)$ & $4(20 \%)$ \\
\hline \multicolumn{3}{|l|}{$\begin{array}{c}\text { Frequency of Wine Consumption at Home } \\
\text { (\# Participants) }\end{array}$} \\
\hline Do not usually drink wine at home & $2(10 \%)$ & $2(10 \%)$ \\
\hline $1-3$ times per month & $10(50 \%)$ & $10(50 \%)$ \\
\hline $1-4$ times per week & $8(40 \%)$ & $8(40 \%)$ \\
\hline $5+$ times and above & 0 & 0 \\
\hline \multicolumn{3}{|l|}{$\begin{array}{c}\text { Glasses of Wine Consumed in a Restaurant } \\
\text { (\# Participants) }\end{array}$} \\
\hline Do not usually drink wine in restaurant & $8(40 \%)$ & $5(25 \%)$ \\
\hline $1-3$ glasses & $12(60 \%)$ & $14(70 \%)$ \\
\hline $4+$ glasses & 0 & $1(5 \%)$ \\
\hline Wine Involvement Score & 4.1 & 4.6 \\
\hline
\end{tabular}




\subsection{Taiwanese Hierarchical Value Map}

Figure 2 presents the Hierarchical Value Map of attributes, consequences and values of Taiwanese participants. Taiwanese participants were primarily driven by the attribute "Price" of wine and "Sensory Aspects" of wines. From this study, it was found that $90 \%$ of the Taiwanese participants mentioned taking the price of wine into consideration. It was revealed that a number of the participants would pick wines from a higher price range when dining in a restaurant. A Taiwanese participant reasoned his choice of purchasing a more expensive wine in a restaurant,

"I don't drink wine every day. Wine is not an essential item for me personally to drink every day. I only drink it during Lunar New Year or to celebrate birthdays or promotions. We drink when we are happy, when we celebrate with other people."

He further explained that he felt it was reasonable to purchase a more expensive but better quality wine to share and enjoy once in a while, since he was not a frequent drinker. This finding is consistent in a study by Liu and Murphy [9], who found that Chinese consumers in their study purchased more expensive wines in public situations, and were also likely to purchase less expensive wines in private situations.

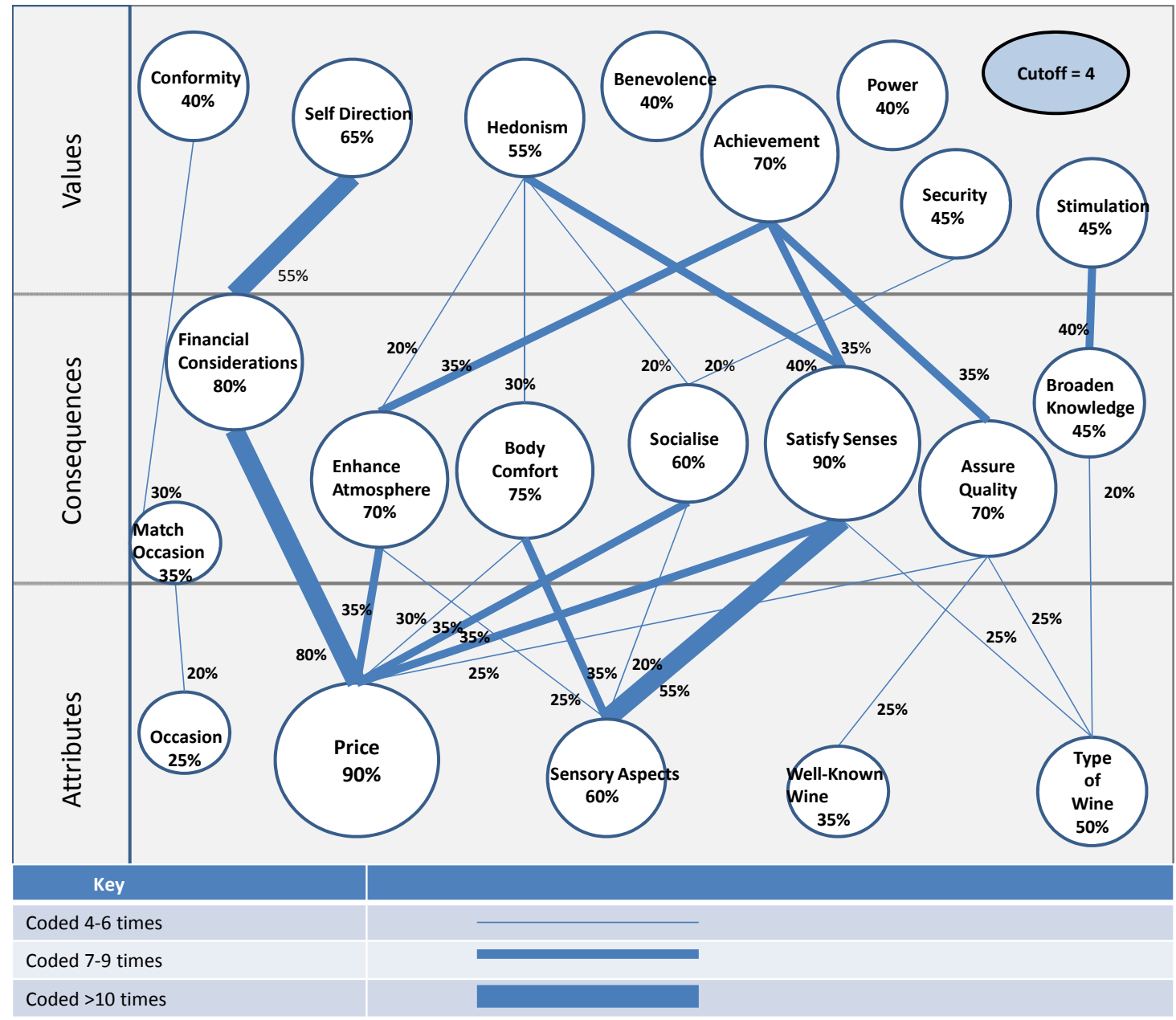

Figure 2. Hierarchical Value Map of Motivation for Buying Wine for Taiwanese Participants.

The attribute "Sensory Aspects" of wine was the second most mentioned by Taiwanese participants, where $60 \%$ of the Taiwanese participants mentioning it as one of the most important aspects they would consider. The descriptions related to "Sensory Aspects" were often related to the 
color of wine, alcohol level and also the sweet-dry attributes of wines, which were the aspects usually mentioned by most Taiwanese.

The third most mentioned attribute was "Type of Wine", which included the wine variety and the country of origin, with $50 \%$ of the Taiwanese stressing its importance. An interesting finding from Liu and Murphy [9] was that although the Chinese consumers showed a preference for French wines, however this was not found with the Taiwanese participants in this study. This discrepancy is surprising given that French wines currently hold the largest market share in Taiwan in 2008-2012 [4]. On the other hand, perhaps the nature of questioning in the value laddering interviews was focused on participants' answers on generic attribute (e.g., country of origin), rather than on providing background information per se on the attribute itself (e.g., preferred country of origin is France).

While a thorough understanding of each of the individual attributes, consequences and values in and of themselves is important, some previous scholars have stressed the importance of focusing analysis on the links between concepts [37]. Thus, for the purpose of understanding the Taiwanese participants' consumer choice, attention will now be focused on the understanding the linkages within the means-end chain framework.

The attribute-consequences linkages and their percentages are shown in Table 3. A total of 15 links were formed between attributes and consequences. Among the Taiwanese participants, the consequences "Financial Considerations", "Satisfy Senses", "Socialize", "Enhance Atmosphere" and "Body Comfort" were all linked to the attribute "Price", with varying linkage strengths. The strongest of these links was between the attribute "Price" and the consequence "Financial Considerations" $(80 \%)$. "Price" was also uncovered as a means to fulfill consequences such as "Enhance Atmosphere", "Socialize" and to "Satisfy Senses". These three consequences shared the same percentage of participants who made the linkages between the attribute and the consequences (35\%). There were two links between "Sensory Aspects" and consequences, "Satisfying Senses" (55\%) and "Body Comfort" (35\%).

Table 3. Taiwanese Participants' Attributes-Consequences Links and Percentages.

\begin{tabular}{cc}
\hline Attributes-Consequences & Percentages \\
\hline Price-Financial Considerations & $80 \%$ \\
Sensory Aspects-Satisfy Senses & $55 \%$ \\
Price-Socialise & $35 \%$ \\
Price-Satisfy Senses & $35 \%$ \\
Sensory Aspects-Body Comfort & $35 \%$ \\
Price-Enhance Atmosphere & $30 \%$ \\
Price-Body Comfort & $30 \%$ \\
Price-Quality Assurance & $25 \%$ \\
Sensory Aspects-Enhance Atmosphere & $25 \%$ \\
Well-known Wine-Assure Quality & $25 \%$ \\
Type of Wine-Satisfy Senses & $25 \%$ \\
Type of Wine-Assure Quality & $25 \%$ \\
Occasion-Match Occasion & $20 \%$ \\
Sensory Aspects-Socialise & $20 \%$ \\
Type of Wine-Broaden Knowledge & $20 \%$ \\
\hline
\end{tabular}

Many Taiwanese participants mentioned that they relied on price to make their decision on their wine choice,

"I don't drink much so I don't know anything about wine. So price is the most logical thing I rely on when I buy wine. As the saying goes, "you get what you pay for", I believe that the more expensive the wine is, the better quality it is."

Limited wine knowledge was one of the main reasons as to why these consumers relied on important cues such as "Price" to assure the quality of wine, and also to show status associated 
to "Mian $\mathrm{Zi}$ " (Face) $[9,11]$. This study also found that the dining companions greatly influence the Taiwanese participants' (and also Malaysian participants') choice of price, for example,

"It depends on who I am with, if I am with a very important client, I will buy a more expensive wine, but if I am with my friend, I am more relaxed (in terms of price, usually indicating a cheaper priced wine)."

This finding supports Heine [38], who found that East Asians were more likely to find themselves fulfilling different societal obligations on different occasions (such as when interacting with people with different statuses). Hence, in a host-client situation, East Asian hosts are more likely to purchase more expensive wines to treat someone with a higher social status.

The Hierarchical Value Map elicited by the Taiwanese participants showed a link between "Sensory Aspects" and "Body Comfort". The Taiwanese participants regularly mentioned that they typically select wines for their alcohol content (categorized into the "Sensory Aspects" attribute), to fulfill the consequence "Body Comfort" which refers to both feeling comfortable and the feeling of "high" after the consumption of wine. The Taiwanese participants placed a strong emphasis on this aspect, with $75 \%$ of the participants mentioning using this wine attribute to fulfill this consequence ("Body Comfort"),

"Because when you drink wine, it will bring you a certain effect. For example, wine with strong alcohol (high alcohol level) will make you dizzy, and red wine, perhaps has a better effect in that. It's hard to explain, people say that red wine warms you up, you should feel more comfortable and relaxed. It would make the night perfect."

Additionally, they also related "Body Comfort" as feeling comfortable with the sensory aspects of the wine,

"When I drink it, I feel very happy, very comfortable. My body will feel very comfortable. Throat will feel warm, the good wine."

Moreover, the Taiwanese participants had also elicited frequent alcohol consumption would affect their health ("Body Comfort") in the future if too much alcohol was consumed,

"Occasionally when you go to a dinner, a drink or two is the limit no more. Because it will affect your health, your family, and the lives of everyone around you. You might get cancer. You really don't want to do that to yourself and your family. It is very irresponsible."

This participant related her concerns for her health if she consumed too much alcohol. This finding is common also for the Chinese and Taiwanese culture to associate wine drinking with health, and is supported by a number of research related to wine drinking and culture $[9,11]$.

The Taiwanese participants' consequences-values links and percentages are demonstrated in Table 4. The link between "Satisfying Senses" and "Hedonism" is the most prominent consequencesvalues link amongst Taiwanese participants. This is not surprising to observe this link as "Hedonism" encapsulates pleasure and enjoyment in life, typically found in research where luxury food or beverage (i.e., wine) was the subject of interest. Sensory satisfaction when drinking wine is a part of enjoyment in life.

The link "Financial Considerations-Self Direction" was the second strongest link in the Taiwanese participants' Hierarchical Value Map. According to Schwartz [35], "Self-Direction" represents the independent spectrum of the value structure, in which an individual is capable of choosing his or her own goal. The ability of these participants to self-govern and be able to be in charge of their spending showed a high sense of "Self Direction".

An interesting find for the Taiwanese group was the "Socialize-Security" link being apparent in the Hierarchical Value Map. The Taiwanese participants relied socializing with friends to have a more secure future, 
"The reason why I said socializing is important is because it will help improve relationships between my friends and me, we get to know each other better, and when I am in trouble they will help me, or when they are in trouble, I will help them. This is how we take care of each other."

The Taiwanese participants have also linked "Match Occasion" with the value "Conformity". The rationale given by a Taiwanese is,

"It feels more right to buy premium wine in a high class restaurant, because everybody in the restaurant would be doing that, if I buy a cheap wine, it wouldn't feel right, and might look awkward, I don't want to look too out of place."

Another interesting finding is that the Taiwanese participants felt the need to include any educational element to their experience in order to "Broaden their Knowledge", even when they consume wine. Prior studies have noted that East Asians from countries such as China, Hong Kong, Taiwan, Japan, South Korea, Singapore and Malaysia have a strong Confucian influence [39]. As the basis of Confucian's teachings is to seek knowledge, study, and to become a better person [40], it was not surprising to observe that the Taiwanese participants placed a large emphasis on gaining knowledge regardless of occasion. A Chinese adage "huo dao lao, xue dao lao" (Live till old, Learn till old) reflected the mentality of many who still practice Confucianism, and would utilize any opportunity they had (even in wine drinking) to learn about new things in their daily lives to "enrich themselves".

Table 4. Taiwanese Participants' Consequences-Values Links and Percentages.

\begin{tabular}{cc}
\hline Consequences-Values & Percentages \\
\hline Financial Considerations-Self Direction & $55 \%$ \\
Satisfy Senses-Hedonism & $40 \%$ \\
Broaden Knowledge-Stimulation & $40 \%$ \\
Enhance Atmosphere-Achievement & $35 \%$ \\
Satisfy Senses-Achievement & $35 \%$ \\
Assure Quality-Achievement & $35 \%$ \\
Match Occasion-Conformity & $30 \%$ \\
Body Comfort-Hedonism & $30 \%$ \\
Enhance Atmosphere-Hedonism & $20 \%$ \\
Socialise-Hedonism & $20 \%$ \\
Socialise-Security & $20 \%$ \\
\hline
\end{tabular}

\subsection{Malaysian Hierarchical Value Map}

Figure 3 shows the Hierarchical Value Map of Malaysian participants.

The attribute "Sensory Aspects", was the most influential attribute among Malaysian participants, with $65 \%$ of the participants revealing it as an important attribute they would look for in wine. This is quite surprising as existing literature has suggested that the sensory appeal of food was only ranked sixth in the most important factors Malaysians look for in food, and ranked behind "Price" [41]. This discrepancy could be due to the interview question which asked about the consumption of a specific product (i.e., wine) in a certain social context (i.e., a restaurant setting).

Price was the second most mentioned attribute, with $45 \%$ of the Malaysian participants mentioning its importance. Similar to the Taiwanese participants, Malaysian participants also reported that they favored mid- to high-end wine products. What is evident here is that these values do not necessarily mean that East Asians want to spend less on wine but rather they want to spend wisely. The reason given by the Taiwanese and Malaysians for favoring these products was because wine was usually consumed during celebrations, special occasions or with special guests, therefore buying cheaper wine options (which is usually thought to indicate a lower quality) was not optional. Although strong attention was given to the attribute "Occasion" (55\%), there were no apparent strong links made to a higher level of abstraction. 


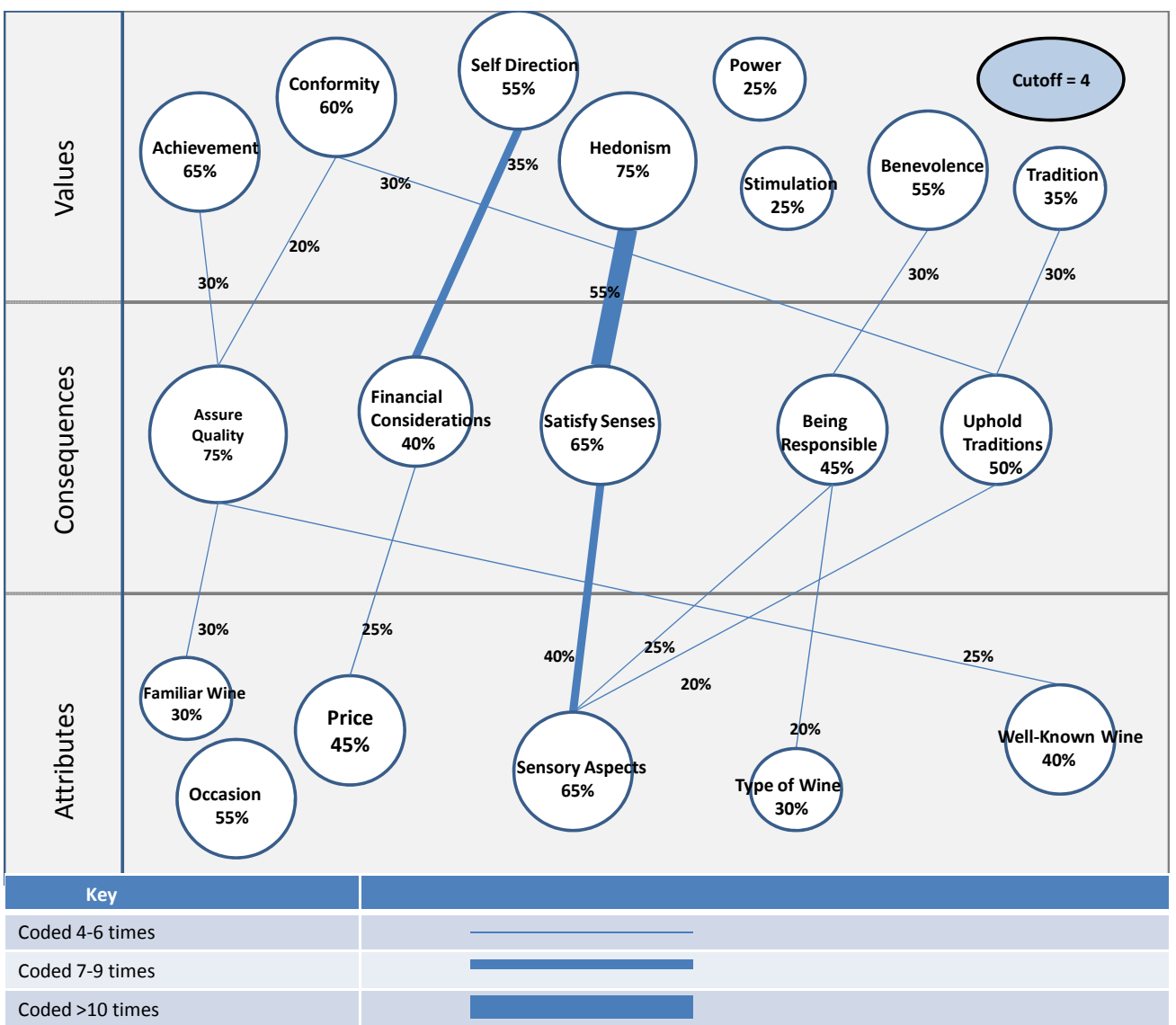

Figure 3. Hierarchical Value Map of Motivation for Buying Wine for Malaysian Participants.

The most common value revealed by the Malaysian participants was "Hedonism" (75\%). This value was also strongly linked to "Satisfying Senses", with 55\% of the Malaysian participants linking the two. "Self Direction" was another value which the Malaysian participants linked to the consequence "Financial Considerations" (35\%). "Achievement" was the second most common value elicited by the Malaysian participants (65\%), followed by "Conformity" with $60 \%$ of the participants eliciting this value. Fifty-five percent of participants revealed that the "Self-Direction" was an important personal value which influenced their choice of wine.

As aforementioned, it is important not to overlook the links between attributes, consequences and values. Table 5 depicts the links between attributes and consequences made by the Malaysian participants.

Table 5. Malaysian Participants' Attributes-Consequences Links and Percentages.

\begin{tabular}{cc}
\hline Attributes-Consequences & Percentages \\
\hline Sensory Aspects-Satisfy Senses & $40 \%$ \\
Familiar Wine-Assure Quality & $30 \%$ \\
Price-Financial Considerations & $25 \%$ \\
Sensory Aspects-Being Responsible & $25 \%$ \\
Well-known Wine-Assure Quality & $25 \%$ \\
Sensory Aspects-Uphold Traditions & $20 \%$ \\
Type of Wine-Being Responsible & $20 \%$ \\
\hline
\end{tabular}

The strongest link made by the Malaysian participants was the "Sensory Aspects-Satisfy Senses" link, which attributed to $40 \%$ of the participants. Malaysians appeared to place a strong emphasis on the sensory satisfaction which is usually obtained from food or beverages, 
"Because we makan (eat) because we enjoy food. We, Malaysians, enjoy our food a lot. Otherwise, you won't see us eating Char Koay Theuw (fried noodles) on dirty streets, if not for the taste of it. Same goes to drinking wine, we drink wines because it is an enjoyment, and taste is there, the atmosphere."

The "Familiar Wine" and "Assure Quality" link was the second most mentioned "Attributes-Consequences" link by the Malaysian participants. An explanation given by a Malaysian participant,

"Because there are so many fake wines around, of course you need to have something that you are sure of to have some quality."

This highlighted the fact that some Malaysian participants had a heightened awareness of food safety on wines, especially for wines that were imported from China.

In some cases, an attribute may be linked to a value directly. An example for this is in the Malaysian participants, the "Sensory Aspects" of wines was linked to "Upholding Traditions" (value: "Tradition"). A participant had identified this as a "national activity",

"We go out, we plan to enjoy ourselves, and being Malaysian, food is very important, that's why we have good food, and good drinks, that is what a lot of us, Malaysians are looking for. Malaysians love food, eat all the time. So it is an identity thing."

The Malaysian participants' Consequences-Values links are provided in Table 6.

Table 6. Malaysian Participants' Consequences-Values Links and Percentages.

\begin{tabular}{cc}
\hline Consequences-Values & Percentages \\
\hline Satisfy Senses-Hedonism & $55 \%$ \\
Financial Considerations-Self Direction & $35 \%$ \\
Assure Quality-Achievement & $30 \%$ \\
Being Responsible-Benevolence & $30 \%$ \\
Uphold Traditions-Conformity & $30 \%$ \\
Uphold Traditions-Tradition & $30 \%$ \\
Assure Quality-Conformity & $20 \%$ \\
\hline
\end{tabular}

The link "Satisfying Senses-Hedonism" was the strongest "Consequences-Values" link made by the Malaysian participants, with 55\% of the participants making the link. This link was one of the most prominent ones made by the Taiwanese participants.

The link "Financial Considerations-Self Direction" was the second strongest link made by the Malaysian participants. In Schwartz's [31] research, "Self-Direction" represents the independent spectrum of the value structure, in which an individual is capable of choosing his or her own goal. The ability of these participants to self-govern and be able to be in charge of their spending showed a high sense of "Self Direction". A Malaysian participant explained,

"If I buy wines that are within my budget, I don't have to spend unnecessarily. So, that money can be put into good use, like saving for my kids' future, or if I want to buy a house in the future, I know I have some money to do so."

The link "Upholding Traditions-Conformity" is a unique one to Malaysian participants. Even though wines are a reasonably new beverage to be introduced into the East Asian culture and diet, they have been used vastly during celebratory occasions $[9,11]$. Considering the context in which Malaysians consume their wines, a suggestion is that wine consumption has become part of a tradition during these celebrations, therefore the Malaysian see it as something natural to have during a special occasion. Additionally, this display is consistent with an interview excerpt of a participant who explained that she did not really like the taste of wine but she drank them because her friends and family usually drink wine during celebratory occasions, 
"I don't usually like the taste of wines, but I buy them because it is the thing everyone does when they celebrate a special occasion, so I follow suit."

"The joy of enjoying food is what we learned since young, and it is what we had been exposed to. Whether it is enjoying wine or something else, it is something that is ingrained into us. And it is also our identity, as Malaysians, we don't have a lot of things that we share in common with others from different races, but our love of food is what ties us together."

Alcohol content of the wine plays an important role amongst Malaysian participants. As aforementioned, "Sensory Aspects" and "Type of Wine" attributes were frequently stated often in the context of the alcohol content of wine. This lead to a consequence of being a responsible drinker, so that they do not drink too much alcohol and cause many unnecessary problems like, being involved in a car accident, and cause harm to the people around them. This has led to a value "Benevolence", where the participants place strong emphasis on not wanting to harm other people, caused by over-drinking.

"Hedonism" was a value widely mentioned by Malaysian participants, $(75 \%$ of the population sample) and this was strongly linked to "Satisfy senses". This link can be attributed to the Malaysian's mentality which emphasized on attaining pleasure and enjoyment from food. This can be seen in the example from the interview,

"Because as Malaysians, we enjoy eating food, eating food is what we live for, it makes us feel happy.

That's why we have so many successful "kopitiams" (hawker stalls) around, we can just sit there, enjoy our food and with good companies, this is what we live for, right?"

\section{Practical Marketing Implications and Recommendations}

The Hierarchical Value Maps have revealed that both cultural groups have elicited a sizable amount of attributes, consequences and values associated to their wine choice. As expected, some similarities were shown within the Taiwanese and Malaysian Hierarchical Value Maps. The two Hierarchical Value Maps depicted several similar dominant attributes, such as "Price" and "Sensory Aspects" of wine, consequences such as "Satisfying Senses", "Assure Quality", and the values "Hedonism" and "Achievement" and "Self Direction". The well-known marketing 4P framework [42] is now used to explain the practical marketing implications derived from these results. Each of the $4 \mathrm{P}^{\prime} \mathrm{s}$ in the framework (i.e., Product, Price, Promotion, and Place) and their relevant resulting implications are discussed in turn.

The Product refers to the items purchased by the consumer, in this case, wine. This may include all the attributes associated to the wine, such as packaging, type of wine, year, or brand that are sold with it. Recognizable wine labels were found to be one of the important criteria for both Taiwanese and Malaysian participants. These consumers particularly looked for brands they are exposed to or brands that have been heavily endorsed by friends or known media, such as blogs. Wine exporters targeting the foodservice (restaurant) sector will therefore have to be prepared to spend time and money creating brand recognition in these countries for their products' labels. Given the expense of television advertising, and the importance endorsements by friends, this is perhaps best done through the use of social media. A "Facebook" site that allows followers to "like" the product and then encourage its followers to forward the site onto their friends through internet competitions or promotion specials, would be one such example of how a company could work on building the required brand recognition. Companies also need to ensure that once they have established a well-known brand and a resulting foothold in the wine market, that they remain consistent in their labeling overtime given this importance on recognizable brand labels.

Instead of considering strongly the physical attributes of wine such as wine type, Taiwanese and Malaysian consumers usually rely on price and recommendations to determine their purchase. Due to the lack of an active search for wine information, a simplified labeling system (e.g., with a scale to indicate the sweetness level of wine or its flavor spectrum) may encourage these consumers to be more involved in their wine purchase decisions, as they will be able to be more in control in terms of 
choosing their wines for themselves, instead of relying on price cues and recommendations from the waiter. By empowering these East Asian consumers with the basic knowledge of how to make their own decisions on wine, it might encourage them to play a more active role in searching for information when buying wine in the future.

Consistent with another study's finding [10], the current study revealed that East Asians generally prefer red wine over white wine due to exposure, traditional beliefs, and general liking for stronger tastes. The results do indicate however, that there is market potential for white wines. Successful introduction of white wines might be enhanced by exposing consumers to the wines by food pairing to increase their knowledge and familiarity of white wines, especially in younger age groups. The reason for targeting young working class groups is due to their enthusiasm and willingness to try new things. By using food pairing, the participants can learn the important elements in wine which would complement food, thus fulfilling their need to broaden their knowledge. This would provide the consumers with sensory satisfaction from sampling different wine-food combinations. While such awareness and behavioral change initiatives will be important to grow this product sector, it is also important that the emphases of such promotions are now of turning white wine drinking into more than a fashionable trend. Although most Taiwanese and Malaysians are trend-focused, and while this may thus result in short-term successes, it will not be feasible over the long run if the desired outcome is sustained growth of this market.

Most participants mentioned that good wine packaging is very important and they placed a strong emphasis on this to help them make their choice. A display of the selling point of the wine (such as the country of origin), an indication that the wine is a premium product, or a classy design label, would allow the consumer to display the wine bottle on the table, thus allowing him or her to have "Mian Zi" (face) among his or her guests.

Both Taiwanese and Malaysian participants showed specific sensory preferences for wines that are sweeter and they mentioned they would prefer fruitier tasting wine as compared to other wine tastes. Wines with lower alcohol content were also said to be preferred by many of these participants. This is linked to the fact that the participants often drink wine in a restaurant to enhance their "Mian $\mathrm{Zi}^{\prime \prime}$ but not necessarily for the taste. Hence, by modifying the drinks to suit the East Asian palates would allow these consumers to have a pleasant wine drinking experience and would subsequently encourage brand loyalty. Furthermore, East Asian's general lower tolerance for alcohol means that having lighter wine alcohol content would allow East Asian consumers to have a choice to opt for a healthier option of wine.

Price is the amount that consumers indicated that they would be prepared to pay for the wine. Many Taiwanese and Malaysian participants pointed out that price was a major influencing attribute that helped determine their wine purchase decision in the restaurant setting. Among the Taiwanese participants, price was considered to be a mark of quality, therefore there seemed to be a fairly common agreement that they would be willing to spend a bit more to help ensure that a quality wine was purchased.

Several studies have highlighted a situation where many consumers from East Asian countries had limited knowledge of wines, a situation echoed by the research findings of this study. The lack of knowledge of wine created the situation where the price of wine was used by participants as an indicator for quality of wine, instead of the intrinsic factors of the wine itself. Many of these participants interviewed pointed out that they commonly used price as a guideline for quality assurance to ensure wines to be within their acceptable quality range, and they often assumed that the higher the price, the better the quality. However, as mentioned before, this might not necessarily mean that they would purchase and consume wines that are of the highest price range, due to their discipline in prioritizing the use of money. Imported wines from Western countries are generally the wine of choice for these participants due to their perception of class and quality. Therefore, the price-related marketing implication is to offer consumers in these markets wines that are within the mid-high range 
of price in the wine market in these two countries with special attention given to the packaging to evoke class and quality.

Promotion is the marketing of wine and all the activities which support wine selling. Considering the Taiwanese and Malaysian participants often mentioned that they generally consumed wine during celebrations, it is important for exporters to be aware of celebratory occasions, such as Lunar New Year, where wine would be consumed, to ensure intensive promotions of wines during these times. Offering limited edition wines with elements of the celebration such as having one of the zodiac signs on the labels for each Lunar New Year, or with offering wines with unique flavor to the occasion, such as having mandarin orange flavor notes (mandarin orange is also considered as an auspicious fruit among the Taiwanese and Malaysian Chinese community, especially during Lunar New Year) in wine for Lunar New Year, may appeal to the interest of these consumers.

Offering sponsorship or funding to community events may increase the product awareness of such wines. Wine has been viewed as a high-class drink, and is often only drunk in more sophisticated social events which are in contrast to beer (which is a more common beverage of choice in Asia and is drunk in almost any event including at concerts, parties, and sports bars). Sponsoring community events such as sports events would not only increase awareness of this product, but also helps the participants form an associative connection between wines and casual good times, and emphasizes the fact that it is not just a product to be consumed in a restaurant or special celebration.

Health is another selling point for wines. Many of the health-oriented East Asians stated that they drunk red wines to improve their health, as they believe in its various health benefits in improving blood circulation and heart disease preventions. Echoing Benedictine D.O.M., a liqueur made by Bacardi, which targeted mothers who are in confinement (Asian women are usually not allowed to leave the house for a month after giving birth), red wines could be advertised as a healthier alcohol option to middle-aged consumers, as there were already relevant clinical studies showing the benefits of drinking red wine in middle-aged groups. Also, this is the age group that expressed more concerned about their health.

Taiwanese participants identified "Broadening Knowledge" as one of the consequences which influenced their wine-purchasing behavior. This means that the Taiwanese associate seeking knowledge while consuming wine as part of a good drinking experience. By providing information on how wines are produced, the history of wine production, or information on the health benefits from drinking an appropriate amount of wine can gain the attention of these Taiwanese consumers. This can be done either by enclosing a booklet with the wine packaging, or by giving proper training to the waiters for them to present the knowledge surrounding wine to the Taiwanese patrons in the restaurant or events where wine is served.

In a highly collectivistic community, such as Malaysia and Taiwan, trend-following is not a surprising phenomenon to observe among these two cultures. Peer pressure and their cultural predisposition to discourage bringing attention to themselves by being unique or different, lead these consumers to aspire to follow the status quo of the community. By having trends that are considered fashionable would drive these consumers to like mainstream product better, compared to products that are unique or special. As the emphasis on individualistic image is not as strong, as compared to the Western countries, the effort to making wine products unique and personalized should not be given as much attention as with the West. Instead, promoting "Best Selling" wines may increase the chance of individuals purchasing and consuming wines, rather than promoting a product which targets a niche.

Place refers to where the wine is being sold (i.e., in a social environment, restaurant). From this study, it appeared that most of the East Asian participants associate wine drinking as a joyous affair. Wines are commonly purchased and consumed during weddings, New Year, Lunar New Year, birthdays, anniversaries and other occasions to which a large number of guests are invited. Using wines as toasts are common in both these cultures, as it encourages a happy atmosphere and convivial spirit amongst the celebrants. Taking into account that most Taiwanese and Malaysian participants 
have a tendency to hold huge celebrations and feasts during these occasions, it is wise to offer specials or promotions in restaurants or catering services where participants may purchase bulk wines for cheaper prices.

Red wine is usually offered during these special occasions, regardless of the dishes served. White wines are sometimes offered during these occasions, and they are less likely to be consumed due to the lack of exposure and knowledge. Even though there is an overall lack of wine knowledge compared to Western consumers, the interviewed participants still stated that they were able to discriminate good or bad wine pairing. Therefore, it is important to not overlook this aspect when promoting wine.

Additionally, marketers who are interested in venturing into Asian markets have to have background knowledge on how food is usually served in Asian restaurants, where special occasions are usually celebrated and where wines are generally consumed. East Asian cultures typically practice communal eating and a Chinese restaurant would usually serve a variety of food on the same time. This means that there would be different types of meats, chicken or fish on the same time. It is highly different from the West, where meals are usually served individually and generally consist of appetizer, main and dessert. This makes it difficult to determine proper wine pairing. Having recommendations on the label itself, designed by wine specialists or connoisseurs who are also used to the Eastern cuisine would assist the consumers in making wiser wine choices. Another way of doing so is by recommending restaurants to promote food and wine packages, where the menu would have two different types of wines (red and white) served to complement each dish. The restaurant could also slow down the time for each sequential dish to be served, to allow enough time for the participants to savor each meal with complementary wines.

While this study focused on a restaurant setting to evoke attributes, consequences and values of wine consumption, there are obviously other retail outlets that sell wine including the increasingly popular wine shops and wine bars in Taiwan and Malaysia. As the results indicated that both cultures held a common interest to pursue knowledge about wines while enjoying them, it is worthwhile for retailers in these settings to provide tips and information about the origin of the wine, the wine making process, wine storage, and other general knowledge about wine for consumers to read at the point of purchase. Exporting companies are recommended to provide this information via brochures, posters and other such information media for display in such setting to accompany their products on the shelves.

\section{Conclusions}

This research found a range of attributes, consequences and values which motivated the purchase of wine amongst Taiwanese and Malaysian participants. Table 7 highlights the top three most dominant attributes, consequences and values elicited by Taiwanese and Malaysian participants.

Table 7. Top three most dominant attributes, consequences and values by Taiwanese and Malaysian participants.

\begin{tabular}{ccc}
\hline & Taiwanese & Malaysian \\
\hline \multirow{3}{*}{ Attributes } & Price & Sensory Aspects \\
& Sensory Aspects & Occasion \\
& Type of Wine & Price \\
\hline \multirow{3}{*}{ Consequences } & Satisfy Senses & Assure Quality \\
& Financial Considerations & Satisfy Senses \\
& Enhance Atmosphere & Uphold Tradition \\
\hline \multirow{2}{*}{ Values } & Achievement & Hedonism \\
& Self-Direction & Achievement \\
& Hedonism & Conformity \\
\hline
\end{tabular}


This has been a small scale exploratory study. While incredibly deep (and thus extremely useful) insights were obtained into the values underpinning wine consumption behaviors, the small sample size obviously means that care must be taken to not over-generalize the findings beyond the sample population. The results rather, serve as a good basis for further exploration and more quantitative validation. An example of a fruitful future research study would be the comparison of the Hierarchical Value Maps of high versus low-involvement segments of consumers within each of these countries. It should be noted that the ladders in this research cannot be claimed to represent the sole causes or drivers of wine purchasing behavior. Another obvious area for research would be to consider how other explanatory variables interact with the consumers' personal values identified in this study. Nevertheless, the "ladders" do give insights into the consequences that people derive from certain wine attributes and how these link to their personal values which, as outlined in the previous section, has a number of useful implications for influencing purchase behavior in this area. Eventually, one application of these results will be to find out which segments of respondents are most likely to share the same values and rationalizations so that marketing campaigns can target these people appropriately.

One of the limitations of this study was the fact that the sample was taken from Taiwanese and Malaysian consumers in New Zealand. The Western influence within New Zealand may have had an impact on some of the participants' attitudes and behaviours. However the criteria were set that all respondents had to have not been in New Zealand for more than a year. This was to minimize bias and hopefully ensure the participants still had strong connections to their home countries. It is important to view the laddering results in the context of the study as opposed to a true representation of the two respective populations. In a similar vein, other successful studies have been done in the past in which Chinese immigrants have been used as a sample for investigations into Chinese perceptions or beliefs [43,44]. This study warrants the exploration of the validity of these findings with a wider, more representative, study in Taiwan and Malaysia.

This study made two contributions: Firstly, this study contributes to the understanding of means-end chain literature related to food purchasing processes by exploring the influence of Taiwanese and Malaysian culture on means-end chain for wine choice. Secondly, this study offers practitioner-orientated contribution, notably, concrete suggestions are provided to wine exporters interested in targeting the East Asian countries-Taiwan and Malaysia.

Acknowledgments: The authors would like to thank the University of Otago for the research funding received.

Author Contributions: Miranda Mirosa was responsible for the conceptual and methodological design of the project, overall project management and revising the manuscript. Sharon Tang (MAppSc) conducted all of the fieldwork and analysis and wrote the first draft of the manuscript.

Conflicts of Interest: The authors declare no conflict of interest.

\section{References}

1. New Zealand Trade and Enterprise, Export: Wine in China. Available online: http://www.nzte.govt.nz/ en/export/market-research/wine/wine-in-china/ (accessed on 20 September 2015).

2. Anderson, K.; Nelgen, S. Global Wine Markets, 1961-2009: A Statistical Compendium; University of Adelaide Press: Adelade, Australia, 2011.

3. Index Mundi. Taiwan Demographics Profile 2014. Available online: http://www.indexmundi.com/taiwan/ demographics_profile.html (accessed on 20 September 2015).

4. Australian Trade Commission. Taiwan: Trends and Opportunities. Available online: http://www.austrade. gov.au/Export/Export-Markets/Countries/Taiwan/Industries/Wine\#.UowNhsRMRng (accessed on 20 September 2015).

5. Lee, K. Taiwan Wine Market Grows More Diverse; USDA Foreign Agricultural Service: Idaho, ID, USA, 2013.

6. New Zealand Trade and Enterprise, Export: Food and Beverage Market in Malaysia. Available online: http:/ / www.nzte.govt.nz/en/export/market-research/food-and-beverage/food-and-beverage-market-inmalaysia/ (accessed on 20 September 2015). 
7. Malaysia: A Reality Check. Available online: http://exportermagazine.co.nz/articles/malaysia-reality-check (accessed on 20 September 2015).

8. Euromonitor International. Country Report: Wine in Malaysia. Available online: http://www.euromonitor. com/wine-in-malaysia/report (accessed on 20 September 2015).

9. Liu, F.; Murphy, J. A qualitative study of Chinese wine consumption and purchasing: Implications for Australian wines. Int. J. Wine Bus. Res. 2007, 19, 98-113. [CrossRef]

10. Fu, T. Healthy and decreasing price-Foreign wines are selling better. Beijing Xian Dai Shang Bao $2004, \mathrm{C} 12$.

11. Balestrini, P.; Gamble, P. Country-of-origin effects on Chinese wine consumers. Br. Food J. 2006, 108, $396-412$. [CrossRef]

12. Gutman, J. A means-end chain model based on consumer categorization processes. J. Market. 1982, 26, 60-72. [CrossRef]

13. Mennell, S.; Murcott, A.; van Otterloo, A. The Sociology of Food: Eating, Diet and Culture; SAGE: London, UK, 1992.

14. Overby, J.W.; Gardial, S.F.; Woodruff, R.B. French versus American consumers' attachment of value to a product in a common consumption context: A cross-national comparison. J. Acad. Market. Sci. 2004, 32, 437-460. [CrossRef]

15. Gardial, S.F.; Clemons, D.S.; Woodruff, R.B.; Schumann, D.W.; Burns, M.J. Comparing consumers' recall of prepurchase and postpurchase product evaluation experiences. J. Consum. Res. 1994, 20, 548-560. [CrossRef]

16. Bredahl, L. Consumers' cognitions with regard to genetically modified foods. Results of a qualitative study in four countries. Appetite 1999, 33, 343-360. [CrossRef] [PubMed]

17. Connors, M.; Bisogni, C.; Sobal, J.; Devine, C. Managing values in personal food systems. Appetite 2001, 36, 189-200. [CrossRef] [PubMed]

18. Kirchhoff, S.; Smyth, H.; Sanderson, J.; Sultanbawa, Y.; Gething, K. Increasing vegetable consumption: A means-end chain approach. Br. Food J. 2011, 113, 1031-1044. [CrossRef]

19. Le Page, A.; Cox, D.; Russell, G.; Leppard, P. Assessing the predictive value of means-end-chain theory: An application to meat product choice by Australian middle-aged women. Appetite 2005, 44, 151-162. [CrossRef] [PubMed]

20. Lee, P.; Lusk, K.; Mirosa, M.; Oey, I. The role of personal values in Chinese consumers' food consumption decisions. A case study of healthy drinks. Appetite 2014, 73, 95-104. [CrossRef] [PubMed]

21. Nie, C.; Zepeda, L. Lifestyle segmentation of US food shoppers to examine organic and local food consumption. Appetite 2011, 57, 28-37. [CrossRef] [PubMed]

22. Tang, S. Exploring the Transferability of Value Laddering for Understanding East Asian Consumer Choice. A Cross-Cultural Study on Wine. Master's Thesis, University of Otago, Dunedin, New Zealand, 2013.

23. Bordeaux-Rego, B.; Nedwed-Machado, F.; de Oliveira, M.O.R.; Alves, D.A.; Slongo, L.A. “Why caipirinha?"-The online via chat laddering technique CAN answer. BAR Braz. Adm. Rev. 2011, 8, 150-167. [CrossRef]

24. Frust, T.; Connors, M.; Bisogni, C.; Sobal, J.; Falk, L. Food choice: A conceptual model of the process. Appetite 1996, 26, 247-266. [CrossRef] [PubMed]

25. Grunert, K.G.; Grunert, S.G. Measuring subjective meaning structures by laddering method: Theoretical considerations and methodological problems. Int. J. Res. Market. 1995, 12, 209-225. [CrossRef]

26. Biernacki, P.; Waldorf, D. Snowball sampling: Problems and techniques of chain referral sampling. Sociol. Methods Res. 1981, 10, 141-163.

27. Saaka, A.; Sidon, C.; Blake, B.F. Laddering: A "How to Do It" Manual-With a Note of Caution. 2004. Available online: http://academic.csuohio.edu/cbresearch/papers/Good\%20PDFs/Laddering_A\%20 How\%20to\%20do\%20it\%20manual.pdf (accessed on 20 September 2015).

28. Reynolds, T.J.; Gutman, J. Laddering theory, method, analysis, and interpretation. J. Advert. Res. 1988, 28, 11-31.

29. Veludo-de-Oliveira, T.M.; Ikeda, A.A.; Campomar, M.C. Laddering in the practice of marketing research: Barriers and solutions. Qual. Market Res. Int. J. 2006, 9, 297-306. [CrossRef]

30. Botschen, G.; Thelen, E. Hard versus Soft Laddering: Implications for Appropriate Use. In New Developments and Approaches in Consumer Behaviour Research; Balderjahn, I., Mennicke, C., Vernette, E., Eds.; Schaffer-Poeschel Verlag \& Mecmillan Press Ltd.: Stuttgart, Germany; Houndmills, London, UK, 1998.

31. Zaichowsky, J.L. Measuring the involvement construct. J. Consum. Res. 1985, 12, 341-352. [CrossRef] 
32. Braun, V.; Clarke, V. Using thematic analysis in psychology. Qual. Res. Psychol. 2006, 3, 77-101. [CrossRef]

33. Larkin, P.J.; de Casterle, B.D.; Schotsmans, P. Multilingual translation issues in qualitative research: Reflections on a metaphorical process. Qual. Health Res. 2007, 17, 468-476. [CrossRef] [PubMed]

34. Huberman, A.M.; Miles, M.B. Qualitative Data Analysis: An Expanded Sourcebook, 2nd ed.; SAGE: London, UK, 2002.

35. Schwartz, S.H. Are there universal aspects in the structure and contents of human values? J. Soc. Issues 1994, 50, 19-45. [CrossRef]

36. Schwartz, S.H. Value hierarchies across cultures: Taking a similarities perspective. J. Cross Cult. Psychol. 2001, 32, 268-290. [CrossRef]

37. Fotopoulos, C.; Krystallis, A.; Ness, M. Wine produced by organic grapes in Greece: Using means-end chains analysis to reveal organic buyers' purchasing motives in comparison to non-buyers. Food Qual. Preference 2003, 14, 549-566. [CrossRef]

38. Heine, S.J. Self as cultural product: An examination of East Asian and North American Selves. J. Personal. 2001, 69, 881-906. [CrossRef]

39. Lee, W.O. The cultural context for Chinese learners: Conceptions of learning in the Confucian tradition. In The Chinese Learner: Cultural, Psychological and Contextual Influences; Watkins, D.A., Biggs, J.B., Eds.; Comparative Education Research Centre (CERC) \& Australian Council of Educational Research (ACER): Hong Kong, China, 1996; pp. 63-67.

40. Chen, G.M.; Chung, J. The impact of Confucianism on organizational communication. Commun. Q. 1994, 42, 93-105. [CrossRef]

41. Prescott, J.; Young, O.; O’Neill, L.; Yau, N.J.N.; Stevens, R. Motives for food choices: A comparison of consumers from Japan, Taiwan, Malaysian and New Zealand. Food Qual. Preference 2002, 13, 489-495. [CrossRef]

42. Kotler, P.; Zaltman, G. Social marketing: An approach to planned social change. J. Market. 1971, 35, 3-12. [CrossRef]

43. Lee, P.Y.; Lusk, K.; Mirosa, M.; Oey, I. Effect of information on Chinese consumers' acceptance of thermal and non-thermal treated apple juices: A study of young Chinese immigrants in New Zealand. Food Qual. Preference 2016, 48, 118-129. [CrossRef]

44. Zhang, T.; Lusk, K.; Mirosa, M.; Oey, I. Understanding young immigrant Chinese consumers' freshness perceptions of orange juices: A study based on concept evaluation. Food Qual. Preference 2016, 48, 156-165. [CrossRef]

(C) 2016 by the authors; licensee MDPI, Basel, Switzerland. This article is an open access article distributed under the terms and conditions of the Creative Commons by Attribution (CC-BY) license (http:/ / creativecommons.org/licenses/by/4.0/). 